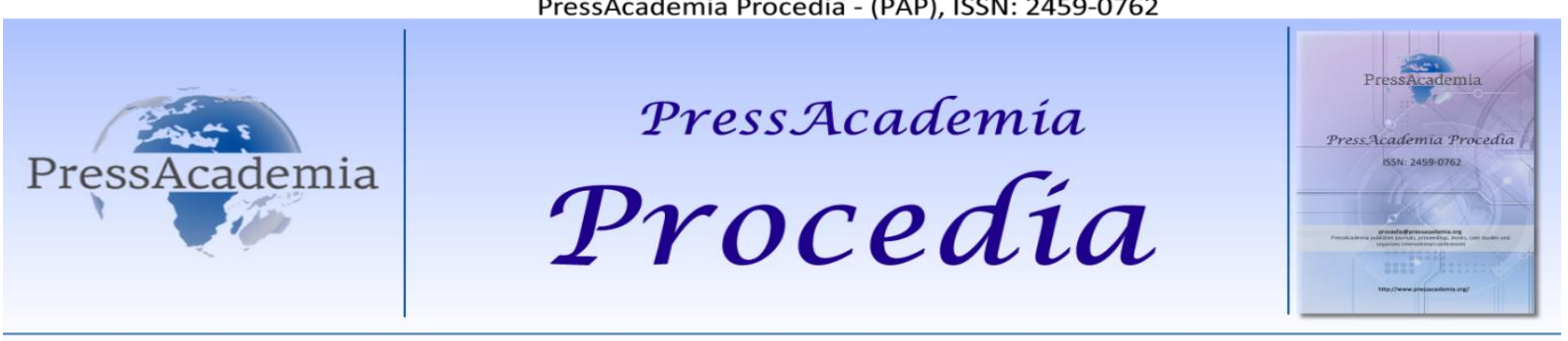

Global Business Research Congress (GBRC), May 24-25, 2017, Istanbul, Turkey

\title{
EFFECTS OF CUSTOMER ENGAGEMENT BEHAVIOR ON CUSTOMER LOYALTY
}

\section{DOI: 10.17261/Pressacademia.2017.636 \\ PAP- GBRC-V.3-2017(62)-p.599-608}

\section{Ercan Taskin ${ }^{1}$, Fatma Demirag ${ }^{2}$}

${ }^{1}$ Dumlupınar Üniversitesi, IïBF, Kütahya, Türkiye, Ercan.taskın@dpu.edu.tr

${ }^{2}$ Dumlupınar Üniversitesi, Uygulamalı Bilimler Yüksekokulu, Kütahya, Türkiye, fatma.demirag@dpu.edu.tr

To cite this document

Taskin, E. E and F. Demirag (2017). Effects of customer engagement behavior on customer loyalty. PressAcademia Procedia (PAP), V.3, p.599-608.

Permemant link to this document: http://doi.org/10.17261/Pressacademia.2017.636

Copyright: Published by PressAcademia and limited licenced re-use rights only.

\begin{abstract}
In this research, personal caring service field consumer are analyzed consumer behavior participation effect of the customers loyalty. This research is considered as a descriptive study, personal caring service consumers structured questionnaire administered data was obtained by convenience sampling method. In data analyze, data was obtained with factor analysis, hypothesis testing was performed with regression analysis. According to the results obtained from the research; customer engagement behavior positively affects the of the behavioral and attitudinal loyalty. And attitudinal loyalty positively affects behavioral loyalty. In enterprises providing personal care services, the effect of customer participation behavior on customer loyalty is examined. In this process, firstly literature based evaluations are given and interpretations are made according to the analyzes made for the variables discussed later.Suggestions are provided to practitioners and future studies. Research is an exploratory research.Survey was used as data collection tool in the research.The questionnaire was formed in two parts in order to measure the effect of demographic variables and customer participation behavior on customer loyalty. Customer participation behavior is examined in four dimensions; information seeking, information sharing, responsible behavior, personnel communication.Customer loyalty is examined in two dimensions as loyalty and behavioral loyalty.Dimensions of customer participation behavior in research Yi and Gong, (2013); Attitude and behavioral loyalty are adorned from the work of Kuikka and Laukkanen, (2012). Expressions in the scales were evaluated as "I definitely agree - 5 I definitely do not agree" as the five-point Likert scale. It has been found that customer participation behaviors positively affect loyalty and behavioral loyalty, whereas attitudinal loyalty affects behavioral loyalty positively. As a result of the data obtained within the scope of the research; All hypotheses have led to the conclusion that accepted customer participation behavior positively affects behavioral loyalty and attitudinal loyalty positively affects behavioral loyalty.
\end{abstract}

Keywords: Loyalty, Customer Participation Behavior, Customer Loyalty, Contingent Loyalty, Behavioral Loyalty JEL Codes: M3, M30, M31

\section{MÜŞTERI KATILIM DAVRANIŞININ MÜŞTERI SADAKATINE ETKISI}

\section{ÖZET}

Bu çalışama da kişisel bakım hizmeti alan müşterin katılım davranışlarının müşteri sadakatine etkisi incelenmektedir. Araştırma tanımlayıcı araştırma niteliğindedir. Veriler kişisel bakım hizmeti alan tüketicilere uygulanan yapılandırılmış anketle kolayda örnekleme yöntemiyle elde edilmiştir. Verilerin analizinde açıklayıcı faktör analizi ile boyutlar elde edilmiş, hipotezler ise regresyon analizi ile test edilmiştir. Araştırmadan elde edilen sonuçlara göre; müşteri katılım davranışının tutumsal sadakate ve davranışsal sadakate, tutumsal sadakatin ise davranışsal sadakate olumlu etkilediği tespit edilmiştir. Kişisel bakım hizmeti sağlayan işletmelerde müşteri katılım davranışının müşteri 
sadakatine etkisini incelemektir. Bu süreçte öncelikle literatüre dayalı değerlendirmelere yer verilmekte daha sonrasında ele alınan değişkenlere yönelik yapılan analizlere göre yorumlar yapılmakta uygulayıcılara ve gelecek çalışmalara öneriler sunulmaktadır. Araştırma keşfedici bir araştırma niteliğindedir. Araştırmada veri toplama aracı olarak anket kullanılmıştır. Anket formu demografik değişkenler ve müşteri katılım davranışının müşteri sadakatine etkisini ölçmek amacıyla iki bölümden oluşturulmuştur. Müşteri katılım davranışı bilgi arayışı, bilgi paylaşma, sorumlu davranma, personel iletişimi olmak üzere dört boyutta incelenirken; müşteri sadakati tutumsal sadakat ve davranışsal sadakat olmak üzere iki boyutta incelenmektedir. Araştırmada müşteri katılım davranışı boyutları Yi ve Gong, (2013); tutumsal ve davranışsal sadakat ise Kuikka ve Laukkanen, (2012) çalışmalarından adapte edilmiştir. Ölçeklerde yer alan ifadeler beşli likert ölçeği "1 Kesinlikle Katılıyorum - 5 Kesinlikle Katılmıyorum" şeklinde değerlendirilmiştir. Müşteri katılım davranışının tutumsal sadakate ve davranışsal sadakate, tutumsal sadakatin ise davranışsal sadakate olumlu etkilediği tespit edilmiştir. Araştırma kapsamında elde edilen veriler sonucunda; bütün hipotezler kabul edilmiş müşteri katılım davranışının tutumsal sadakate ve davranışsal sadakate, tutumsal sadakatin ise davranışsal sadakate olumlu etkilediği sonuçlarına varılmıştır.

Anahtar Kelimeler: Sadakat, Müşteri Katılım Davranışı, Müşteri Sadakati, Tutumsal Sadakat, Davranışsal Sadakat JEL Kodları: M3, M30, M31

\section{GíRiş}

Özellikle hizmet üreten işletmelerde pazarlamacı ve tüketiciler tarafından ortak olarak yaratılan ürünün değişimi; kullanım öncesinde, sırasında ve sonrasında sosyal olarak inşa edilmektedir ( Dedeoğlu, 2015: 25). Tüketici ile ortak değer yaratarak tüketiciyi yenilik sistemlerine dâhil etmek ve tüketicilerin deneyimlerini zenginleştirmek ve onları yaratıcı hale getiren birlikte yaratma müşteri katııı davranışı ve müşteri sorumlu davranış olmak üzere iki temel faktörden oluşmaktadır (Güneş, 2011: 76). Müşteri katılım davranışı gerekli hizmet karşılaşması sırasında müşterilerin eylemi olarak ifade edilmektedir. Müşterilerin bilgi araması, paylaşması, sorumlu davranışı ve kişisel etkileşimi ile müşteriler ortak bir değer yaratma faaliyetine katılarak işletmelerde ilişkileri geliştirerek sadakate olumlu katkı sağlamaktadırlar. Her gün yeni ürünlerin pazara girdiği pazar koşullarında rekabet edebilmek, devamlılı̆̆ sağlamak, kar elde etmek gibi amaçları gerçekleştirebilmek için işletmeler var olan müşterilerini sadık müşterilere dönüştürme arayışına girmişlerdir. Müşteri sadakati bir işletmenin maddi olmayan duran varlıklarından biridir. Sadakat literatür incelendiğinde genel olarak davranışsal ve tutumsal sadakat olmak üzere iki farklı boyutta kavramsallaştırılııstır (Usta ve Memiş, 2009: 2; Villacé-Molinero vd., 2016: 2). Sadakatin tutum ve davranış boyutları rekabet avantajı için büyük bir potansiyele sahip olduğu için araştırmacılar özellikle hizmet pazarlamasında katılım ve sadakat konularına odaklanmıştır (Tachis ve Tzetzis, 2015: 8). Bu çalışmanın amacı da kişisel bakım hizmeti sağlayan işletmelerde müşteri katılım davranışının müşteri sadakatine etkisini incelemektir. Bu süreçte öncelikle literatüre dayalı değerlendirmelere yer verilmekte daha sonrasında ele alınan değişkenlere yönelik yapılan analizlere göre yorumlar yapılmakta uygulayıcılara ve gelecek çalışmalara öneriler sunulmaktadır.

\section{LITERATURE INCELEMESI}

\subsection{Müşteri Katılım Davranışı}

Hizmetlerin başarılı üretim ve teslimat için beklenen gerekli davranışları gösterme şeklinde tanımlanan müşteri katıımı davranışı, özellikle hizmet sunumumda istenilen hizmet çıktıları elde edebilmek için önemli bir kavramdır (Chen vd., 2015: 65). Müşteri katılımı davranışı genel bir tanımla değer yaratma sürecindeki her türlü faaliyet olarak tanımlanmaktadır (Yi vd., 2009: 88). Tüketilen ürünlerin üretiminde tüketici tarafından üstlenilen değer yaratma faaliyetleri olan müşteri katılımı (Chen ve Wang, 2016: 346) hizmet ağırlıklı faaliyetlerde rekabet avantajı için önerilen temel faaliyetlerden birisidir (Chen vd., 2015: 486).

Müşteri katııımı davranışı başarıı bir hizmet yaratılması için gerekli bir davranıştır. Müşteri katılım davranışı verimliliği artırır, müşterilerin aktif katılımı ile ortaya konan yaratım ve teslimat işletmenin maliyetlerini düşürür, müşterilerin intiyaçlarının memnuniyetini arttırabilir. Her iki taraf, karşııklı işbirliği yoluyla kazan-kazan durumu yaşarsa taraflar arası ilişkiyi arttırır. Müşterileri ile karı ilişkiler oluşturulmasını etkileyerek sadakati artııı (Camacho vd., 2015: 1610; Sharma vd., 2014: 279). Müşterilerde birlikte yaratma davranışının bir boyutu olan müşteri katılım davranışı dört farklı faktörden oluşmaktadır. Bilgi arama, bilgi paylaşımı, sorumlu davranış ve kişisel etkileşim olmak üzere müşteri katılımı davranışııın dört faktörü bulunmaktadır (Yi ve Gong, 2013: 1279; Silva vd., 2016: 1623; Dong ve Sivakumar, 2015: 726). Bilgi arama; müşteriler hizmet gereksinimlerini açıklamak için hizmet durumu, hizmetin parametreleri ile ilgili ve ortak değer yaratma olarak görevlerini gerçekleştirmek için bilgiyi aramaktadırlar. Bu bilgilerin sağlanması konusunda müşteri belirsizliği azaltmaktadır. Bilgi paylaşımı; başarılı ortak değer yaratılması için, müşterilere bilgi olarak kaynak sağlamalıdır. Çünkü bilgi paylaşımı ortak değer yaratma başarısının anahtarıdır (Vâzquez vd., 2015: 36).Çalışanları bilgi paylaşımı sayesinde, çalışanların müşterilerin belirli ihtiyaçlarını karşılayan bir hizmet sunabileceğine emin olabilirsiniz. Müşterilerin doğru bilgi sağlamak için başarısız olursa, ortak değer yaratma kalitesi düşük olabilir. Bilgi paylaşma ortak değer oluşturma boyut için 
hayati önem taşımaktadır (Yi ve Gong, 2013: 1279). Sorumlu davranış; müşterilerin kısmi çalışanlar olarak kendi görev ve sorumluluklarını tanımasıdır. Kendileri ve çalışanları arasındaki başarılı ortak değer yaratılması için, müşterilerin kuralları ve politikaları benimsemesi gerekmektedir (Yi ve Gong, 2013: 1279). Birlikte değer yaratma sürecinde müşteriler çalışanlar ile işbirliği içinde olmalıdır (Vâzquez vd., 2015: 36). Kişisel etkileşim; kişisel etkileşim başarılı ortak değer yaratılması için gerekli olan müşteriler ve çalışanlar arasındaki nezaket, samimiyeti ve saygı gibi kişiler arası ilişkileri ifade eder. Bir hizmet bağlamında ortak değer yaratma sosyal bir ortamda daha keyifli, olumlu gerçekleşir(Yi ve Gong, 2013: 1279). Literatürde müşteri katılım davranışına yönelik farklı sektörlerde yapılan çeşitli çalışma yer almaktadır. Bozacı ve Durukan, 2015'de müşteriyi güçlendirmenin faktörlerinden biri olan müşteri katılımının algılamalara etkilerine, Zhang vd., 2015' de teknolojik ortamlarda ortak yaratılış etkileri ve müşteri katılımına, Santos ve Spring, 2015'de bilgi yoğunluklu iş hizmetlerinde müşteri katılımının eksikliğinin aşımasına, Wang vd., 2015'de sanal marka topluluklarda müşteri katılım davranışına, Teng ve Chang, 2016' da otelin çevre dostu programları için müşteri katılımı niyeti artırılmasını, Chae ve Ko, 2016'da müşterin sosyal sosyal ağ hizmetlerinde katılımın motivasyonuna yönelik çalışmalar yapmışlarıdır.

\subsection{Müşteri Sadakati}

1980'lerin başında etkili olmaya başlayan sadakat kavramı ürünler, mal ve hizmet üreten işletmeler (örneğin; oteller, perakendeciler, finansal olarak sanayi, kurumları, araç kiralama şirketleri süpermarketler, havayolu sektörü vd.) gibi oldukça geniş bir alanda etkili olmaktadır (Vaitone ve Papsiene, 2016: 110). Pek çok sektörde etkili olduğu kabul edilen sadakat bir pazarlama enstrümanı olarak benimsenmektedir. Sadakat kavramı tüketicilerin bir markaya, ürüne ya da işletmeye bağııık düzeyini yansıtan bir kavramdır (Khıabanıan ve Karakadılar, 2016: 63). Mevcut müşterilerde oluşan sadakat ise; işletmeleri en önemli rekabet avantajı sağlayacak kaynaklarından birisidir. Çünkü sadakatinin oluşturulması, işletmelerin varlığını sürdürmesi ve kar elde etmesini sağlayan önemli bir yol olarak değerlendirilmektedir (Akdoğan ve Şener, 2015: 10). Ayrıca sadık müşteriler daha fazla satın alma, ödeme ve aldıkları ürün hakkında olumlu davranışlarla işletmelere sayısız faydalar sağlamaktadırlar (Han ve. Woods,2014: 176). Müşteri sadakati kavramı genellikle ürünlere karşı pozitif tutum sergileyip tekrar satın almakla ifade edilebilir Karışık yapısından dolayı farklı perspektiflerde incelenen müşteri sadakati davranışsal sadakat ve tutumsal sadakat olmak üzere iki şekilde incelenmektedir (Çatı vd., 2010: 433; Silva. vd, 2016: 1622; Oyman, 2002: 170; Han ve. Woods,2014: 176). Sadakat davranışlarını doğrudan gözlemlemek her zaman mümkün değildir. Araştırmacılarda genellikle davranışlar ve tutumlar sadakati ölçmek için sık kullanılan yaklaşımlardır (Tanford, 2013: 287).

Müşteri sadakati tutumsal boyutta değerlendirildiğinde; müşteri tatmini sadakatin belirleyici olmaktadır. Tutumsal sadakat, belirli bir ürün, marka, işletme için tüketicilerin bağlılık derecesi, daha fazla ödeme istekliliği olarak tanımlanır (Ong vd., 2016: 4). Müşteriler ile psikolojik ya da duygusal bağ kurma hatta olumlu, çekici ifadeler ile tekrar satın alma yönünde bir ürün veya markaya doğru olumlu bir tutum şeklinde gösterilmesi tutumsal sadakat anlamına gelmektedir (Villacé-Molinero vd., 2016: 2). Müşteri sadakati davranışsal boyutta değerlendirildiğinde; tekrarlanan satın alma davranışı sadakatin belirleyici olmaktadır. Davranışsal sadakat müşteriler devamlılı̆ını korumak için daha yüksek bir eğilimli olarak belirli bir ürün veya marka için satın alma durumu olarak tanımlanabilir(Ong vd., 2016: 4). Davranışsal sadakat; davranış yoluyla ifade edilen taahhütleri kapsamaktadır. Sadakatın bu boyutunda gerçek tekrar satın alma önemlidir. Çünkü sadakat tekrar ziyaret etme sayısı bakımından ölçülür (Villacé-Molinero vd., 2016: 2; Prentıce, 2013: 310). Literatürde müşteri sadakatinin tutumsal ve davranışsal sadakat boyutuna yönelik çeşitli çalışma yer almaktadır., Hong ve Cho, 2011'de tüketicilerin tutumsal sadakat ve satın alma niyetlerinin etkisi, Tarıq , 2015'de arabulucu olarak tutumsal sadakatın marka varlığındaki riskten kaçınma ve davranış sadakat arasındaki ilişkiyi, Bilgihan vd., 2016'da hizmet pazarlamasında davranışsal sadakatin aracı etkisini, Villacé-Molinero vd.,2016'da çoklu bayilerde satış bağlılık programlarında müşteri davranışsal sadakati etkileyen faktörleri, Quintal ve Phau, $2016^{\prime}$ da öğrencilerin üniversitelerinin tavsiye etme veya gönüllü çalışma davranışsal sadakat niyetlerini incelemişledir.

\section{VERI VE YÖNTEM}

\subsection{Araştırmanın Amacı}

Müşteriyi üretim sistemine dâhil ederek ve müşterilerin katılım davranışı göstermeleri başarılı bir ürün ortaya koymakta ve sonrasında karlı ilişkiler oluşarak sadakat artmasında etkili olmaktadır. Bu kapsamda araştırma kişisel bakım hizmeti satın alan müşterilerin katılım davranışının müşteri sadakatine etkisini incelemeyi amaçlamaktadır. Araştırma amaçları doğrultusunda literatür taraması esnasında elde edilen bilgiler ile kuramsal yapı oluşturulmuştur.

\subsection{Araştırmanın Yöntem ve Modeli}

Araştırma keşfedici bir araştırma niteliğindedir. Araştırmada veri toplama aracı olarak anket kullanılmıştır. Anket formu demografik değişkenler ve müşteri katılım davranışının müşteri sadakatine etkisini ölçmek amacıyla iki bölümden oluşturulmuştur. Müşteri katılım davranışı bilgi arayışı, bilgi paylaşma, sorumlu davranma, personel iletişimi olmak üzere dört boyutta incelenirken; müşteri sadakati tutumsal sadakat ve davranışsal sadakat olmak üzere iki boyutta 
incelenmektedir. Araştırmada müşteri katılım davranışı boyutları Yi ve Gong, (2013); tutumsal ve davranışsal sadakat ise Kuikka ve Laukkanen, (2012) çalışmalarından adapte edilmiştir. Ölçeklerde yer alan ifadeler beşli likert ölçeği "1 Kesinlikle Katılıyorum - 5 Kesinlikle Katılmıyorum" şeklinde değerlendirilmiştir. Araştırmada güvenirliği ve ölçeğin homojen bir yapı gösterdiğini test eden Cronbach's Alpha değeri dikkate alınmıştır. Değerin sosyal bilimlere ait çalışmalarda 0,50'den büyük olması arzu edilen bir durumdur (Çokluk vd., 2010: 177-178; Kalaycı, 2014: 322).

Şekil 1: Araştırma Modeli

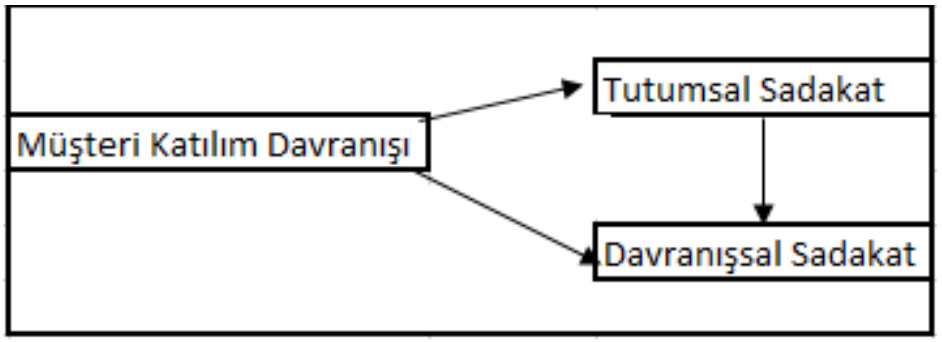

Araştırma kapsamında hazırlanan ölçek internette oluşturulan link aracılılığıyla basit tesadüfî örneklem yoluyla kişisel bakım hizmeti alan müşterilere uygulanmıştır. Araştırmada ana kütle büyüklüğünün belirlenmesinde tam olarak belirlenememiş modellerde 384 olması gerektiği belirlenmiştir (Gegez, 2010: 223; Büyüköztürk vd. 2014: 95).Araştırmada ulaşılan 408 katılımcı örneklem büyüklüğü için yeterli sayıyı sağladığı ve evren hakkında öngörülerde bulunabilmek için yeterli bulunduğu düşünüldüğünden veri toplama süreci sonlandırılıp analizler yapılmıştır.

\subsection{Araştırmanın Hipotezler}

Bilgehan vd., 2016'da tutumsal sadakatin duygular ve davranışsal sadakat arasındaki ilişkiyi aracılık ettiğinden tutumsal sadakat davranışsal sadakati olumlu etkilediği. Han ve. Woods,2014'de etkinin, bilincin, niyetin davranışsal sadakati olumlu etkilediği, Tachis ve Tzetzis, 2015'de yaptıkları çalışmalarında taraftarların katıım davranışının psikolojik, davranışsal ve tutumsal bağııık yarattığı, Giner ve Rillo, 2016'da birlikte yaratma ve güvenin sadakati olumlu etkilediği, Silva vd., 2016'da birlikte yaratma davranışııı tutumsal ve davranışsal sadakati olumlu etkilediği şeklinde hipotez kurmuşlarıdır. Yapılan çalışmalardan yola çıkılarak söz konusu çalışmanın hipotezleri kurulmuştur.

H1:Müşteri katılım davranışı tutumsal sadakati etkilemektedir.

H2: Müşteri katılım davranışı davranışsal sadakati etkilemektedir.

H3: Tutumsal sadakat davranışsal sadakati etkilemektedir.

\section{BULGULAR VE TARTIŞMA}

Elde edilen veriler araştırma amaçları ve araştırma hipotezleri doğrultusunda analiz edilmiştir.

\subsection{Demografik Özelliklere Ait Bulgular}

Araştırmaya katılan katılımcılara yönelik frekans ve yüzde dağılımları Tablo 1'de gösterilmektedir.

Tablo 1: Katılımcıların Demografik Özellikleri

\begin{tabular}{|c|c|c|c|c|c|c|c|}
\hline & & Frekans & Yüzde & & & Frekans & Yüzde \\
\hline \multirow{2}{*}{ Cinsiyet } & Kadın & 284 & 69,6 & \multirow{5}{*}{ Eğitim } & ilkokul & 20 & 4,9 \\
\hline & Erkek & 124 & 30,4 & & Ortaokul & 20 & 4,9 \\
\hline \multirow{4}{*}{ Yaş } & $18-28$ & 196 & 48 & & Lise & 76 & 18,6 \\
\hline & $26-33$ & 80 & 19,6 & & Lisans & 236 & 57,8 \\
\hline & $34-41$ & 72 & 17,6 & & Lisan Üstü & 56 & 13,7 \\
\hline & 42 ve üzeri & 60 & 14,7 & \multirow{3}{*}{ Meslek } & Öğrenci & 176 & 43,1 \\
\hline \multirow{2}{*}{ Gelir } & 1000 TL ve altı & 208 & 51 & & Memur & 112 & 27,5 \\
\hline & $1001-2000$ & 44 & 10,8 & & Esnaf & 28 & 6,9 \\
\hline
\end{tabular}




\begin{tabular}{|c|c|c|c|c|c|}
\hline $2001-3000$ & 60 & 14,7 & Ev Hanımı & 40 & 9,8 \\
\hline 3000 TL ve üzeri & 96 & 23,5 & Emekli & 16 & 3,9 \\
\hline & & & Diğer & 36 & 8,8 \\
\hline Total & 408 & 100 & Total & 408 & 100 \\
\hline
\end{tabular}

Tablo 1' e göre; araştırmaya katılan katılımcılar \%69,6 bayanlardan oluşurken, \%30,4 erkeklerden oluşmaktadır. Katıımcıların yaşları dikkate alındığında ise en fazla katılımcı \% 48 oranında 18-28 yaş arasındaki katılımcılar olduğu, gelirleri dikkate alındığında \%51'inin geliri 1000 TL ve altı olduğu görülmektedir. Katılımcıların eğitim durumlarında ise en fazla oran; $\% 57,8$ ile lisans iken meslekleri ise en fazla oran \%43,1 öğrenci olduğu görülmektedir.

\subsection{Araştırmanın Geçerliliği ve Güvenilirliği}

Ölçeklerin güvenilirlik analizine ilişkin araştırma yapılmadan 40 örnek birim üzerinden ön testler gerçekleştirilmiş ve uygulanan anket formunda bazı ifadelerde düzeltme yapılmıştır. Ölçeklerdeki ifadelerin güvenilirliği ise Cronbach Alpha katsayısı ile test edilmiştir. Ölçeğin müşteri katılım davranışına ait güvenilirlik katsayısı 0,834, tutumsal sadakat ölçeğine ait güvenirlik katsayısı 0,698, davranışsal sadakat ölçeğine ait güvenirlik katsayısı 0,615 olduğu görülmektedir. Her bir faktörün güvenilirlik katsayıları 0,6'dan fazla olduğu için ölçeklerin güvenilir olduğu söylenebilir (Kalaycı, 2014: 321-322). Alan araştırması sonucunda elde edilen Cronbach's Alpha değerleri tablolarda yer almaktadır.

Müşteri katııım davranışı, tutumsal sadakat ve davranışsal sadakat faktörlerinin gruplandırılması amacıyla açıklayıcı faktör analizi kullanılmıştır. Analizlerinin sonuçları Tablo 2'de sunulmuştur.

Tablo 2: Müşteri Katılım Davranışı Faktör Analizi Sonuçları

\begin{tabular}{|c|c|c|c|c|}
\hline & $\begin{array}{l}\text { Faktör } \\
\text { Yükleri }\end{array}$ & Alfa & Özdeğer & $\begin{array}{l}\text { Açıllanan } \\
\text { Varyans }\end{array}$ \\
\hline Kişisel Etkileşim & & 0,798 & 4,876 & 34,831 \\
\hline 15.Çalışanlara karşı saygılı davrandım & 0,848 & & & \\
\hline 14. Çalışanlara karşı kibar davrandım & 0,831 & & & \\
\hline 13.Çalışanlara karşı nazik davrandım & 0,708 & & & \\
\hline 12.Çalışanlara karşı dostça davrandım & 0,565 & & & \\
\hline 16.Çalışanlara karşı terbiyesizce davranmadım & 0,547 & & & \\
\hline Bilgi Arayışı & & 0,797 & 1,897 & 13,547 \\
\hline $\begin{array}{l}\text { 6.Çalışan görevini gerçekleştirebilmesi için gerekli bilgileri } \\
\text { çalışana söyledim }\end{array}$ & 0,781 & & & \\
\hline 5.Çalışana uygun bilgi verdim & 0,767 & & & \\
\hline 4.Çalışana ne istediğimi net bir şekilde açıkladım & 0,709 & & & \\
\hline Sorumlu Davranış & & 0,75 & 1,453 & 10,375 \\
\hline 10. Işin gerektirdiği sorumluluklarımı yerine getirdim & 0,792 & & & \\
\hline 9.Yapılması gerekenleri yeterli şekilde yaptım & 0,782 & & & \\
\hline $\begin{array}{l}\text { 11.Çalışanların yönlendirmelerini ve/ veya önerilerini takip } \\
\text { ettim. }\end{array}$ & 0,634 & & & \\
\hline Bilgi Paylaşımı & & 0,715 & 1,085 & 7,752 \\
\hline $\begin{array}{l}\text { 1.Bu hizmetin hangi olanakları sunduğu ile ilgili başkalarından } \\
\text { bilgi almak isterim }\end{array}$ & 0,857 & & & \\
\hline 2.Bu hizmetin nerede verildiği ile ilgili bilgileri araştırıım & 0,826 & & & \\
\hline $\begin{array}{l}\text { 3.Bu hizmeti iyi bir şekilde alan başkalarının nasıl davrandığını } \\
\text { dikkat ederim }\end{array}$ & 0,54 & & & \\
\hline Cronbach Alpha & \multicolumn{4}{|c|}{0,869} \\
\hline KMO Testi & \multicolumn{4}{|c|}{0,801} \\
\hline Barlett's Test of Sphericity & \multicolumn{4}{|c|}{ X $2: 2317,71 ;$ Sig: 0,001} \\
\hline
\end{tabular}


Faktör yapısını ortaya çıkarmak amacıyla açımlayıcı faktör analizi yapılarak bütün maddeler incelenmiştir. Müşteri katılım davranışı ölçeğinde yer alan 16 maddenin kişisel etkileşim, bilgi arayışı, sorumlu davranış, bilgi paylaşımı şeklinde dört faktör altında toplandığı görülmüştür. Bilgi paylaşımında ve sorumlu davranış faktörlerine ait birer ifade binişik değer aldığı ve faktör yapısını bozduğu için ölçekten çıkarılmış, tekrar analiz yapıldığında Tablo 2'deki sonuçlar elde edilmiştir. Açıklayıcı faktör analizi sonucunda elde edilen test değerleri: Barttlett's test değeri 2317,71 $p$ değeri $p=0,001<0,05$ ve KMO test değerinin 0,869 olarak gerçekleşmiştir. Değerler kabul edilebilir sınırlar içinde gerçekleşmiştir.

Tablo 3: Tutumsal Sadakat Faktör Analizi Sonuçları

\begin{tabular}{|c|c|c|c|c|}
\hline & $\begin{array}{c}\text { Faktör } \\
\text { Yükleri }\end{array}$ & Alfa & Özdeğer & $\begin{array}{c}\text { Açıklanan } \\
\text { Varyans }\end{array}$ \\
\hline Tutumsal Bağlılık & & 0,698 & 1,546 & 77,285 \\
\hline $\begin{array}{c}\text { 18.Ben diğer hizmetler içerisinde bu hizmet için daha yüksek bir } \\
\text { fiyat ödemeye istekliyim }\end{array}$ & 0,848 & & \\
\hline 17.Ben bu hizmete daha bağlıyım & 0,831 & & \\
\hline Cronbach Alpha & \multicolumn{3}{|c|}{0,698} \\
\hline KMO Testi & \multicolumn{3}{|c|}{0,5} \\
\hline Barlett's Test of Sphericity & \multicolumn{2}{|c|}{ X2:143,358; Sig: 0,001} \\
\hline
\end{tabular}

Faktör yapısını ortaya çıkarmak amacıyla açımlayıcı faktör analizi yapılarak bütün maddeler incelenmiştir. Tutumsal sadakat ölçeğinde yer alan 2 maddenin tutumsal sadakat şeklinde tek faktör altında toplandığı görülmüştür. Açıklayıcı faktör analizi sonucunda elde edilen test değerleri: Barttlett's test değeri 143,358, $p$ değeri $p=0,001<0,05$ ve KMO test değerinin 0,5 olarak gerçekleşmiştir. Değerler kabul edilebilir sınırlar içinde gerçekleşmiştir.

Tablo 4: Davranışsal Sadakat Faktör Analizi Sonuçları

\begin{tabular}{|c|c|c|c|c|}
\hline & $\begin{array}{c}\text { Faktör } \\
\text { Yükleri }\end{array}$ & Alfa & Özdeğer & $\begin{array}{c}\text { Açıllanan } \\
\text { Varyans }\end{array}$ \\
\hline Davranışsal Bağılık & & 0,698 & 1,448 & 72,382 \\
\hline 20.Ben bu hizmeti satın almaya devam etmek niyetindeyim. & 0,851 & & & \\
\hline 19.Tekrar satın alacak olsam bu hizmeti satın alırım & 0,851 & & & \\
\hline Cronbach Alpha & \multicolumn{3}{|c|}{0,615} \\
\hline KMO Testi & \multicolumn{3}{|c|}{ X2:90,682; Sig: 0,001} \\
\hline
\end{tabular}

Faktör yapısını ortaya çıkarmak amacıyla açımlayıcı faktör analizi yapılarak bütün maddeler incelenmiştir. Davranışsal sadakat ölçeğinde yer alan 2 maddenin davranışsal sadakat şeklinde tek faktör altında toplandığı görülmüştür. AçıklayıCı faktör analizi sonucunda elde edilen test değerleri: Barttlett's test değeri 90,682, p değeri $p=0,001<0,05$ ve KMO test değerinin 0,5 olarak gerçekleşmiştir. Değerler kabul edilebilir sınırlar içinde gerçekleşmiştir.

\subsection{Hipotezlerin Test Edilmesi}

Araştırmanın bağımsız değişkenleri ile bağımlı değişken arasındaki ilişkiyi ölçmek ve hipotezleri test etmek için regresyon analizi kullanıımıştır. Regresyon analizleri sonuçlarına göre $(p<0,05)$ düzeyinde anlamlı ve pozitif yönlü ilişkiler belirlenmiştir. Elde edilen değerler aşağıdaki tablolarda gösterilmektedir.

Tablo 5: Müşteri Katılım Davranışı ile Tutumsal Sadakat Arasındaki Regresyon Analizi Sonuçları

\begin{tabular}{|c|c|c|c|c|c|c|}
\hline Model & & $\begin{array}{c}\text { Standardize } \\
\text { Edilmemiş } \\
\text { Katsayı }\end{array}$ & & $\begin{array}{c}\text { Standardize } \\
\text { Edilmiş } \\
\text { Katsayı }\end{array}$ & & \\
\hline & & B & $\begin{array}{c}\text { Standart } \\
\text { Hata }\end{array}$ & Beta & $\mathrm{t}$ & Sig. \\
\hline 1 & (Sabit) & 0,698 & 0,14 & & 4,998 & 0 \\
\hline & $\begin{array}{c}\text { MUSTERI } \\
\text { KATILIM } \\
\text { DAVRANISI }\end{array}$ & 0,871 & 0,069 & 0,531 & 12,611 & 0 \\
\hline
\end{tabular}




\begin{tabular}{|c|c|c|c|c|c|} 
& & Düzeltilmiş R & & & \\
R:531a & R Square: 0,281 & Square:0,280 & F: 159,05 & Sig: 0,000 & \\
\hline a Bağımlı & & & & & \\
değişken: & & & & & \\
TUTUMSAL & & & & & \\
SADAKAT & & & & \\
\hline
\end{tabular}

Müşteri katılım davranışı ile tutumsal sadakat arasındaki ilişki düzeyini ölçmek için uygulanan regresyon analizi sonucunda hipotezin bağımsız değişkenlerinin bağımlı değişken olan tutumsal sadakati açıklama gücünü gösteren determinasyon katsayısı 0,281 olarak çıkmışır. Bu değer tutumsal sadakatte meydana gelen değişimin \%28,1lik kısmı müşteri katııım davranışı faktörlerince açıklanabilir anlamına gelmektedir. $F$ değeri 159,05 olup, modelin bir bütün olarak $(p=0,001)$ olduğu söylenebilir.

Tablodaki sonuçlara göre bağımsız değişken olan müşteri katılım davranışının, bağımlı değişken olan tutumsal sadakat ile aralarında istatistiksel olarak anlamlı ve pozitif yönlü zayıf ilişki $(\beta=0,871 ; p=0,001)$ olduğu söylenebilir. Bu sonuç, "H1: Müşteri katılım davranışı tutumsal sadakati etkilemektedir." hipotezini doğrulamaktadır.

Tablo 6: Müşteri Katılım Davranışı ile Davranışsal Sadakat Arasındaki Regresyon Analizi Sonuçları

\begin{tabular}{|c|c|c|c|c|c|c|}
\hline Model & & $\begin{array}{c}\text { Standardize } \\
\text { Edilmemiş Katsayı }\end{array}$ & & $\begin{array}{l}\text { Standardize } \\
\text { Edilmiş } \\
\text { Katsayı }\end{array}$ & & \\
\hline & & B & $\begin{array}{l}\text { Standart } \\
\text { Hata }\end{array}$ & Beta & $\mathrm{t}$ & Sig. \\
\hline \multirow[t]{2}{*}{1} & (Sabit) & 0,644 & 0,137 & & 4,687 & 0 \\
\hline & $\begin{array}{l}\text { MUSTERI } \\
\text { KATILIM } \\
\text { DAVRANISI } \\
\end{array}$ & 0,847 & 0,068 & 0,526 & 12,456 & 0 \\
\hline $\mathrm{R}:, 526 \mathrm{a}$ & R Square: 0,276 & $\begin{array}{l}\text { Düzeltilmiş } \\
\text { R Square:0,275 }\end{array}$ & $F: 155,15$ & Sig: 0,000 & & \\
\hline $\begin{array}{l}\text { a Bağımlı } \\
\text { değişken: } \\
\text { DAVRANISSALS } \\
\text { ADAKAT }\end{array}$ & & & & & & \\
\hline
\end{tabular}

Müşteri katılım davranışı ile davranışsal sadakat arasındaki ilişki düzeyini ölçmek için uygulanan regresyon analizi sonucunda hipotezin bağımsız değişkenlerinin bağımlı değişken olan davranışsal sadakati açıklama gücünü gösteren determinasyon katsayısı 0,276 olarak çıkmıştır. Bu değer davranışsal sadakatte meydana gelen değişimin \%27,6lık kısmı müşteri katılım davranışı faktörlerince açıklanabilir anlamına gelmektedir. $F$ değeri 155,15 olup, modelin bir bütün olarak $(p=0,001)$ olduğu söylenebilir. Tablodaki sonuçlara göre bağımsız değişken olan müşteri katılım davranışının, bağımlı değişken olan davranışsal sadakat ile aralarında istatistiksel olarak anlamlı ve pozitif yönlü zayıf ilişki $(\beta=0,847 ; p=0,001)$ olduğu söylenebilir. Bu sonuç, "H2: Müşteri katılım davranışı davranışsal sadakati etkilemektedir." hipotezini doğrulamaktadır.

Tablo 7: Tutumsal Sadakat ve Davranışsal Sadakat Arasındaki Regresyon Analizi Sonuçları

\begin{tabular}{|c|c|c|c|c|c|c|}
\hline & & $\begin{array}{c}\text { Standardize } \\
\text { Edilmemiş Katsayı }\end{array}$ & & $\begin{array}{c}\text { Standardize } \\
\text { Edilmiş Katsayı }\end{array}$ & \\
\hline 1 & Bodel & B & $\begin{array}{c}\text { Standart } \\
\text { Hata }\end{array}$ & Beta & t & Sig. \\
\hline & $\begin{array}{c}\text { TUTUMSAL } \\
\text { SADAKAT }\end{array}$ & 0,968 & 0,102 & & 9,47 & 0 \\
\hline $\begin{array}{c}\text { R Bağımlı değişken: } \\
\text { DAVRANISSAL } \\
\text { SADAKAT }\end{array}$ & R Square: 0,320 & $\begin{array}{c}\text { Düzeltilmiş } \\
\text { R Square:0,318 }\end{array}$ & F: 190,74 & Sig: 0,000 & & \\
\hline
\end{tabular}

Tutumsal sadakat ile davranışsal sadakat arasındaki ilişki düzeyini ölçmek için uygulanan regresyon analizi sonucunda hipotezin bağımsız değişkenin bağımlı değişken olan davranışsal sadakati açıklama gücünü gösteren determinasyon katsayısı 
0,320 olarak çıkmıştır. Bu değer davranışsal sadakatte meydana gelen değişimin \%32 lik kısmı tutumsal sadakat tarafından açıklanabilir anlamına gelmektedir. F değeri 190,74 olup, modelin bir bütün olarak $(p=0,001)$ olduğu söylenebilir.

Tablodaki sonuçlara göre bağımsız değişken olan tutumsal sadakat, bağımlı değişken olan davranışsal sadakat ile aralarında istatistiksel olarak anlamlı ve pozitif yönlü zayıf ilişki $(\beta=0,554 ; p=0,001)$ olduğu söylenebilir. Bu sonuç, "H3: Tutumsal sadakat davranışsal sadakati etkilemektedir." hipotezini doğrulamaktadır.

Tablo 8: Hipotez Testlerine iliş̧kin Özet Değerlendirme

\begin{tabular}{|l|l|}
\hline \multicolumn{1}{|c|}{ Hipotezler } & Sonuç \\
\hline H1: Müşteri katılım davranışı tutumsal sadakati etkilemektedir. & Kabul \\
\hline H2: Müşteri katılım davranışı davranışsal sadakati etkilemektedir. & Kabul \\
\hline H3: Tutumsal sadakat davranışsal sadakati etkilemektedir. & Kabul \\
\hline
\end{tabular}

\section{SONUC}

Müşterilerin daha fazla üretim süreçlerine dahil olmasıyla değişen rollerinin incelendiği bu çalışmada; müşteri katııım davranışının tutumsal bağ|ılığa ve davranışsal bağ|ılığa etkisi, ve tutumsal bağlılı̆̆ın da davranışsal bağ|ıığa etkisine yönelik hipotezler kurulmuş ve test edilmiştir. Araştırma kapsamında elde edilen veriler sonucunda; bütün hipotezler kabul edilmiş müşteri katıım davranışının tutumsal sadakate ve davranışsal sadakate, tutumsal sadakatin ise davranışsal sadakate olumlu etkilediği sonuçlarına varılmıştır. Araştırma kapsamında müşteri katılım davranışının hem tutumsal bağlılığa hem de davranışsal bağlılı̆a pozitif yönde olumlu etkilediği sonucuna varılmıştır. Bu sonuç literatürde yapılan çalışmaları desteklemektedir. Ailawadi vd., 2014' te yaptıkları çalışmada tüketici tutumlarının doğrudan veya dolaylı olarak davranışsal sadakati etkilediği. Han ve. Woods,2014'de etkinin, bilincin, niyetin davranışsal sadakati olumlu etkilediği sonucuna varmışlardır. Ong vd., 2016'da yaptıkları çalışmada duygusal ve rasyonel güvenin hem davranışsal hem de tutumsal sadakati olumlu etkiledikleri sonucuna varmışlardır. Izogo, 2015'de hizmetlerde güvenin, güvenirliğin ve bağılığın tutumsal sadakati olumlu etkilediği sonucuna varmışlardır. Tachis ve Tzetzis, 2015'de yaptıkları çalışmalarında futbol taraftarların katılımı psikolojik, davranışsal ve tutumsal bağlııı yarattığı sonucuna varmışlardır. Wang vd., 2015'de sanal marka topluluklarda müşteri katıım ile ilgili yaptıkları çalışmalarında müşteri katılım davranışının devam etme niyetine olumlu katkı yaptığı sonucuna ulaşmışlardır. Chae ve Ko, 2016'da müşterin sosyal sosyal ağ hizmetlerinde katılımın motivasyona olumlu etkilediği sonucuna ulaşmışlardır. Chen ve Wang, 2016'da yaptıkları havayolunun onlıne check-in sisteminde müşteri katılımı ile değer ortak yaratma müşteri sadakatini olumlu etki yaptığı sonucuna ulaşmışlardır.

Araştırma kapsamında bu sonuç literatürde yapılan çalışmaları desteklemektedir. Silva vd., 2016'da hizmet sektöründe yaptıkları çalışmalarında birlikte yaratma davranışının hem tutumsal sadakati hem de davranışsal sadakati olumlu etkilediği sonucuna varmışlardır. Ayrıca bu sonuca ek olarak tutumsal bağıı̆ı̆ın davranışsal bağlılığa pozitif yönde olumlu etkilediği sonucuna varmışlardır.

Yapılan çalışma da hizmet işletmelerinde müşteri katılım davranışının tutumsal ve davranışsal sadakate olan etkisi uygulamacılara yeni bir bakış açısı kazandırmaktadır. Uygulayıcılar hedef kitlelerini sürece dahil ederek daha fazla yarar sağlayabileceklerdir. Ayrıca yapılan çalışma diğer akademik çalışmalara katkı sağlayabilecek bir kaynaktır. Araştırmada katılımcıların kolayda örneklem yöntemiyle seçilmesi, araştırmanın belli bir sürede tamamlanma zorunluluğundan ve maliyetten dolayı kısıtlanmasına sebep olmuştur. Ayrıca söz konusu çalışmada birlikte yaratma değerinin sadece bir faktörü dikkate alınmış olup gelecek çalışmalarda bir bütün halinde ele alınıp sonuçlar değerlendirilebilir. Gelecek çalışmalarda farklı sektörler, işletmelere veya ürünler üzerinden birbirleriyle kıyaslama yaparak veya tek tek ele alarak uygulanıp sonuçları değerlendirilebilir.

\section{KAYNAKLAR}

AilLAWADi Kusum, , NESLIN Scott A., Y. Luan Jackie, TAYLOR Gail Ayala, (2014), "Does retailer CSR enhance behavioral loyalty? A case for benefit segmentation", Intern. J. of Research in Marketing, 31 156-167.

AKDOĞAN M. Şükrü ve ŞENER Turan, (2015), “Kurum İmajının Müşteri Sadakatine Etkilerinin Ticari Bankalar Üzerinde Değerlendirilmesi: Nevşehir ïli Örneği", Journal of World of Turks, Vol. 7, No. 3.

BiLGiHAN Anil, MADANOGLU Melih, Ricci Peter, (2016) "Service attributes as drivers of behavioral loyalty in casinos: The mediating effect of attitudinal loyalty", Journal of Retailing and Consumer Services, 31,14-21.

BOZACI Ibrahim ve DURUKAN Tülin, (2015)“ Müşteri Güçlendirmenin Ölçülmesi: İç Anadolu'da Bir Uygulama”, İktisadi ve İdari Bilimler Fakültesi Dergisi, Cilt-Sayı: 8 (1) ss: 105-119. 
BÜYÜKÖZTÜRK Şener, ÇAKMAK Kılıç Ebru, AKGÜN Özcan Erken, KARADENiz Şirin, DEMiREL Funda, (2014), Bilimsel araştırma Yöntemleri, Pegem Akademi, Ankara

CAMACHO María Ángeles Revilla, VÁZQUEZ Manuela Vega, SilVA Francisco José Cossío , (2015), “Customer participation and citizenship behavior effects on turnover intention", Journal of Business Research 68 1607-1611.

CHAE Heeju ve KO Eunju, (2016) "Customer social participation in the social networking services and its impact upon the customer equity of global fashion brands", Journal of Business Research.

CHEN Chih-Cheng Volvic, CHEN Chih-Jou, LiN Ming-Ji James, (2015), "The impact of customer participation: the employee's perspective" Journal of Business \& Industrial Marketing, 30/5 486-497.

CHEN Ching-Fu, WANG Jing-Ping, (2016) "Customer participation, value co-creation and customer loyalty e A case of airline online check-in system", Computers in Human Behavior 62, 346e352.

CHENA Sandy C., RAABB Carola ve TANFORD Sarah (2015), "Antecedents of mandatory customer participation in serviceencounters: An empirical study", International Journal of Hospitality Management 46, 65-75.

ÇATI Kahraman, MURAT Cenk, ve GELiBOLU, Levent (2010), “Müşteri Beklentileri İle Müşteri Sadakat Arasındaki illişki: Beş Yıldızlı Bir Otel Örneği”, Ç.Ü. Sosyal Bilimler Enstitüsü Dergisi, Cilt 19, Sayı 1, Sayfa 429-446.

ÇOKLUK Ömat, ŞEKERCIOĞLU Güçlü ve BÜYÜKÖZTÜRK Şener, (2010), Sosyal bilimler için Çok Değişkenli İstatistik SPSS ve LISREL Uygulamaları, Pegem Akademi

DEDEOĞLU ÖZHAN Ayla, (2015), “Değişen Pazaryerinde Tüketici Ve Tüketimin Rolüne İlişkin Yeni Yaklaşımlar: Ortak-Üretim (CoProductıon) Ve Ortak-Yaratma (Co-Creatıon)", Ege Strategic Research Journal , 6 ( 2 ): 17 - 29.

DONG Beibei and SIVAKUMAR K., (2015), "A process-output classification for customer participation in services", Journal of Service Management Vol. 26 No. 5, pp. 726-750.

GEGEZ, Ercan Pazarlama Araştırmaları, Beta Basım, Genişletilmiş üçüncü baskı, 2010.

GINER Gabriela Ribes ve RiLLO Agustín Peralt, (2016), "Structural equation modeling of co-creation and its influence on the student's satisfaction and loyalty towards university", Journal of Computational and Applied Mathematics 291, 257-263.

GÜNEŞ Serkan (2011), “Değer Yaratma Bağlamında Güncel Dört Yenilik Modeli”, Sanat ve Tasarım Dergisi, Sayı 7, ss. 71-89 .

HAN Heesup ve WOODS David Paul, (2014) "Attitudinal and Behavioral Aspects of Loyalty in the Screen-Golf Industry", Journal of Quality Assurance in Hospitality \& Tourism, 15, 175-189.

HONG Ilyoo B., ve CHO Hwihyung, (2011), "The impact of consumer trust on attitudinal loyalty and purchase intentions in B2C emarketplaces: Intermediary trust vs. seller trust", International Journal of Information Management, 31 469-479.

IZOGO Ernest Emeka, (2015), “Determinants of attitudinal loyalty in Nigerian telecom service sector: Does commitment play a mediating role?", Journal of Retailing and Consumer Services23, 107-117.

KALAYCI, Şeref, (2014), SPSS Uygulamaları Çok Değişkenli İstatistik Teknikleri, Asil Yayınevi, 6.Baskı, Ankara

KHIABANIAN HAGHIGH YasamıN ve KARAKADILAR İbrahim Sarper, , (2016)“Marka Sadakati Yaklaşımlarına Etki Eden Öncül Faktörlerin İncelenmesine Yönelik Bir Ampirik Çalışma”, Electronic Journal of Vocational Colleges, pp:60-70.

KUIKKA Anna and LAUKKANEN Tommi, (2012), "Brand loyalty and the role of hedonic value", Journal of Product \& Brand Management 21/7 529-537.

MOLINERO Teresa Villacé, LARA Pedro Reinares, LARA Eva Reinares, (2016), “Multi-Vendor Loyalty Programs: Influencing Customer Behavioral Loyalty?", Frontiers in Psychology, Volume 7.

ONG Chuan Huat, SALLEH Salniza Md., and YUSOFF Rushami Zien, (2016), "The Role of Emotional and Rational Trust in Explaining Attitudinal and Behavioral Loyalty: An Insight Into SME Brands", Gadjah Mada International Journal of Business Vol. 18, No. 1, 1-19.

OYMAN Mine, (2002)“Müşteri Sadakati saglamada Sadakat Programlarının Önemi”, Kurgu Dergisi, S: 19, 169-185.

PRENTICE Catherıne, (2013), "Attitudinal and Behavioral Loyalty Amongst Casino Players in Macau”, Services Marketing Quarterly, 34:309321.

QUINTAL Vanessa, PHAU Ian, (2016), “Comparing student loyalty behavioural intentions across multi entry mode deliveries: An Australian perspective", Australasian Marketing Journal, pp:1-10

SANTOS Juliana Bonomi ve SPRING Martin, (2015), "Are knowledge intensive business services really co-produced? Overcoming lack of customer participation in KIBS", Industrial Marketing Management 50 85-96.

SHARMA Shikha, CONDUIT Jodie, HILL Sally Rao, (2014) "Organisational capabilities for customer participation in health care service innovation", Australasian Marketing Journal 22,179-188. 
SiLVA Francisco-José Cossío, CAMACHO María-Ángeles Revilla , VÁZQUEZ Manuela Vega, FLORENCio Beatriz Palacios, (2016), “Value cocreation and customer loyalty", Journal of Business Research 69, 1621-1625.

TACHiS Stavros ve TZETZiS George, (2015), “The Relationship Among Fans' Involvement, Psychological Commitment, and Loyalty in Professional Team Sports", International Journal of Sport Management Recreation \& Tourism, Vol.18, p.1-25,

TANFORD Sarah, (2013), "The impact of tier level on attitudinal and behavioral loyalty of hotel reward program members", International Journal of Hospitality Management 34, 285- 294.

TARIQ Muhammad Irfan, (2015), "Examınıng The Relatıonshıp Between Rısk Aversıon And Behavıoral Loyalty In The Presence Of Brand Affects And Attıtudınal Loyalty As Medıator: Evidence From Emergıng Market”, Business Management Conference, Vienna.

TENGA, Chih-Ching ve CHANG Jung-Hua (2014), "Effects of temporal distance and related strategies on enhancingcustomer participation intention for hotel eco-friendly programs", International Journal of Hospitality Management 40 92-99.

USTA S VE MEMiş U, (2009), "Hizmet Kalitesi ve Marka Bağlılığı Arasındaki İlişki Üzerine Müşteri Tatminini Aracılık Etkisi, Atatürk Üniversitesi İktisadi ve İdari Bilimler Dergisi.

VAiTONE Neringa Vilkaite, PAPSiENE Palmira, (2016), "Influence of Customer Loyalty Program on Organizational Performance: a Case of Airline Industry", Inzinerine Ekonomika-Engineering Economics, 27(1), 109-116.

VÂZQUEZ VEGA Manuela, CAMACHO Marïa-Ângeles Revilla, SILVA COSSIO Francisco-José, (2015), "Can the customer's value co-creation behavior be measured?", mars - avril.

WANG Yonggui, MAB Shuang (Sara), LiDahui, (2015), "Customer participation in virtual brand communities: The self-construal perspective", Information \& Management 52 577-587.

Yi Youjae ve GONG Taeshik, (2013) "Customer value co-creation behavior: Scale development and validation", Journal of Business Research $66,1279-1284$.

Yi Youjae, NATARAAJAN Rajan, GONG Taeshik, (2011), "Customer participation and citizenship behavioral influences on employee performance, satisfaction, commitment, and turnover intention", Journal of Business Research 64 87-95.

ZHANG Hong, LU Yaobin Bin Wangc, WU Sibin, (2015), "The impacts of technological environments and co-creation experiences on customer participation", Information \& Management 52 468-482. 